\title{
AUTOMATIC HEADLIGHT BEAM INTENSITY SWITCHER
}

\author{
Ramya Dhawle $^{1}$, Rohit Anvekar ${ }^{2}$, Shivaji Kulkarni ${ }^{3}$, Shrihari Durg ${ }^{4}$ \\ ${ }^{I}$ Electronics and Communication, BVBCET, Hubli, Karnataka, India \\ ${ }^{2}$ Electronics and Communication, BVBCET, Hubli, Karnataka, India \\ ${ }^{3}$ Electronics and Communication, BVBCET, Hubli, Karnataka, India \\ ${ }^{4}$ Electronics and Communication, BVBCET, Hubli, Karnataka, India
}

\begin{abstract}
The evolution in the technology of automobiles has reached its peak. One of the most innovative features is the invention of driver less car or an autonomous car. An autonomous car controls the motion, sensor activation and action automatically without any human intervention. Such vehicles ensure high degree of safety, comfort and ease of driving. The project aims at designing a system to be used in such autonomous cars. The project is to develop an automatic headlight beam intensity switcher. Such a system will sense the beam status of opposing vehicle and switch the beam intensity of headlight. A sensor based mechanism is utilized to develop the system. The beam intensity switcher plays a very important role while driving. During night time, when two vehicles approach each other in opposite direction the high intensity headlight creates an effect called "Troxler effect". This effect creates a temporary blindness for some seconds thus resulting in unfortunate accidents. Thus, the high beam of both the vehicles must be switched to low so as to have a comfortable driving. The use of such a device in cars can prevent accidents at night time due to driver inattentiveness and provides an ease of driving. We have used the Arduino UNO board as our microcontroller and application specific sensors. In our project we have designed a device which is a combination of software and hardware coding. The sensor used is a light intensity sensor named BH1750 which has a wide range of sensing capacity. The light sensor takes the "lux " reading of the headlight rays from the opposing vehicle and checks for a threshold value assigned in the coding. Based on the threshold value the beam switches from high to low state and vice-versa when both the vehicles pass by each other. The same process takes place in opposite vehicle too. This device can be implanted on the front part of the car at an appropriate position and angle.
\end{abstract}

Keywords: automatic, low cost, accurate, headlight beam intensity switcher, Troxler effect, sensor based mechanism and lux readings.

\section{INTRODUCTION}

As per some international surveys around the world, most of accidents occur at night time. These accidents are mainly because of driver inattentiveness while driving. Thus an autonomous car will ensure a safe and easy driving without much human intervention. The effect at night time due to high intensity beam too is responsible for fatal accidents. Thus, an automatic beam switcher helps to switch the high beam to low beam even when driver is inattentive, thereby preventing accidents. The project aims at developing a device or a system to sense the intensity of headlight from opposing vehicle and switching the intensity of headlight automatically based on readings from sensor. The operation of system doesn't depend on human actions.

\subsection{Problem Statement}

The problem statement for our project is to design a low cost, accurate, easy to use and automatic headlight beam intensity switcher to switch the beam intensity from either high to low or vice-versa based on sensor inputs so as to provide safety to the driver and assist in driving.

\subsection{Survey}

- Road accidents are more in night than during day due to low visual conditions. [4]

- More than 40 percent of all automobile accidents resulting in death occur at night, despite the fact that there is up to 80 percent less traffic on the road than during the day. (Germany's Federal Statistics Bureau). The major reason is Troxler effect.[3]

- In 2012, road accidents increased by $3.3 \%$ when compared to 2011 (Courtesy: NHTSA- Nat. High. Traffic Safety Admin.)

- The National Safety Council says traffic death rates are three times greater at night then during the day. 


\subsection{Statistics}
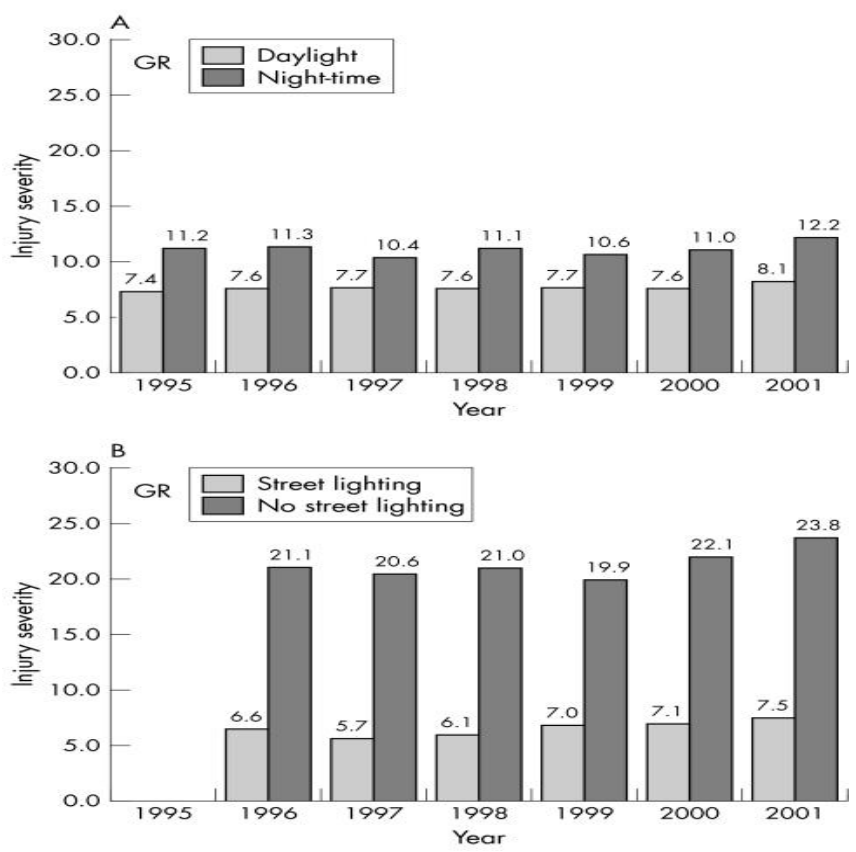

Fig.1 Graph indicating number of accidents at night time as compared to day time.

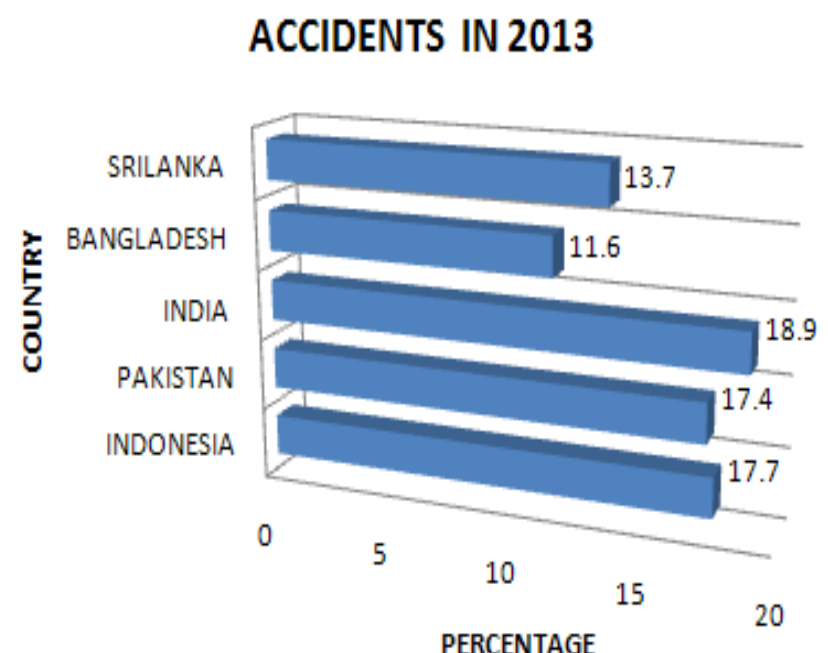

Fig.2-Accident report of Asia due to Troxler effect in 2013

\section{DESIGN PROCESS}

\subsection{Hardware Requirements}

\begin{tabular}{|l|l|l|}
\hline Component & Specification & Quantity \\
\hline Power Supply & $12 \mathrm{~V}, 2.2 \mathrm{~A}$ and 5V & 1 each \\
\hline Arduino Light & BH1750 & 1 \\
\hline $\begin{array}{l}\text { Digital } \\
\text { sensor }\end{array}$ & $5 \mathrm{~V}$ & 2 \\
\hline Relay & $12 \mathrm{~V}, 35 \mathrm{~W}$ & 2 \\
\hline $\begin{array}{l}\text { Headlights (Dual } \\
\text { Filament Bulb) }\end{array}$ & & 4 \\
\hline
\end{tabular}

\subsection{Block Diagram}

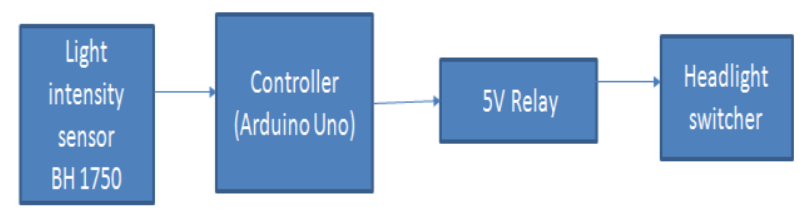

\subsection{Specification of Digital Light Sensor BH1750}

- $\quad \mathrm{I} 2 \mathrm{C}$ bus interface.

- Illuminance to digital convertor.

- Wide range and high resolution (1-65535 lux).

- Low current by power down function.

- $50 \mathrm{~Hz} / 60 \mathrm{~Hz}$ light noise reject function.

- $\quad$ Operating Voltage: $3.3-5 \mathrm{~V}$.

- Dimensions $-21 * 16 * 3.3 \mathrm{~mm}$.

- Influence of IR is very small.

\subsection{Circuit Diagram}

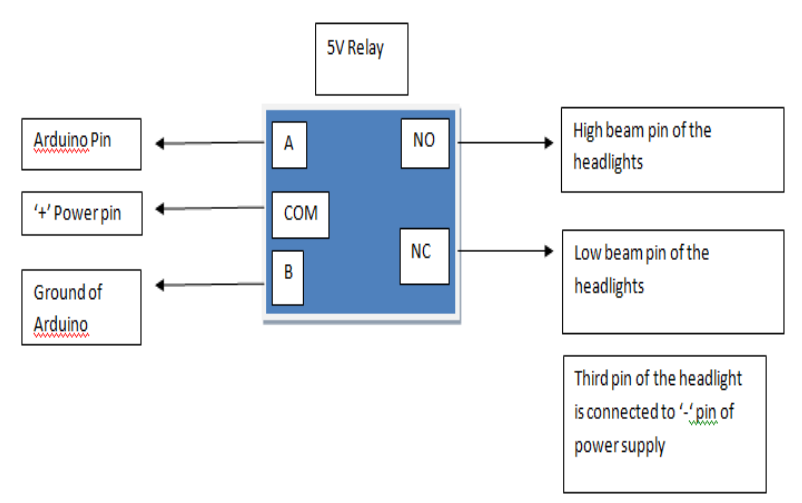

Fig -3: Circuit Diagram of the headlight.

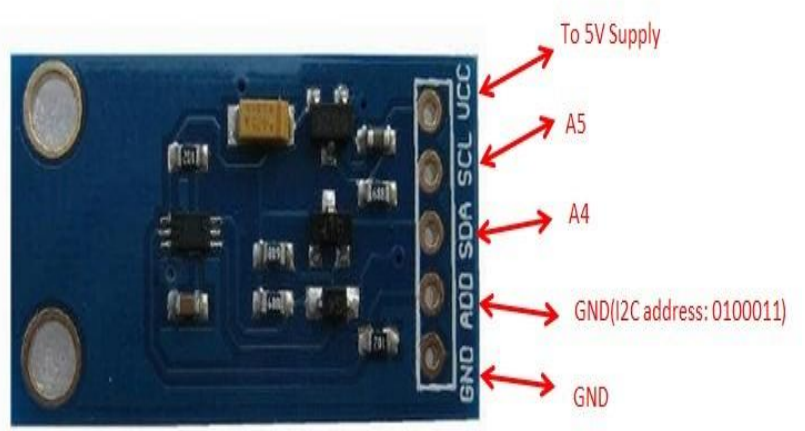

Fig -4: BH1750 connections 


\subsection{Working}

Initially the intensity values from the opposing vehicle are read by the BH1750 digital light sensor. These readings are sent to the Arduino board. If the value exceeds the limit of around 100lux, indicating that the vehicle is nearing us, the device switches the beam of the headlight from high to low using a $5 \mathrm{~V}$ relay. Simultaneously, the similar process takes place in the opposing vehicle as well. Once the vehicles have passed by each other the intensity again goes from low to high. Thus the system automates the headlights and assists the driver.

\subsection{Arduino Code}

/*

Sample code for the BH1750 Light sensor

Website :www.elecrow.com

Connection:

VCC-5v

GND-GND

SCL-SCL(analog pin 5)

SDA-SDA(analog pin 4)

ADD-NC or GND

*/

\#include <Wire.h $>/ /$ BH1750 IIC Mode

\#include <math.h>

int BH1750address $=0 \times 23$; //setting i2c address

byte buff[2];

int led $=11$, led $1=12$;

void $\operatorname{setup}()$

\{

Wire.begin();

Serial.begin(57600);//init Serail band rate

pinMode(led, OUTPUT);

pinMode(led1, OUTPUT); \}

void loop()

\{

int $\mathrm{i}$;

uint16_t val=0;

BH1750_Init(BH1750address);

$\operatorname{delay}(200)$;

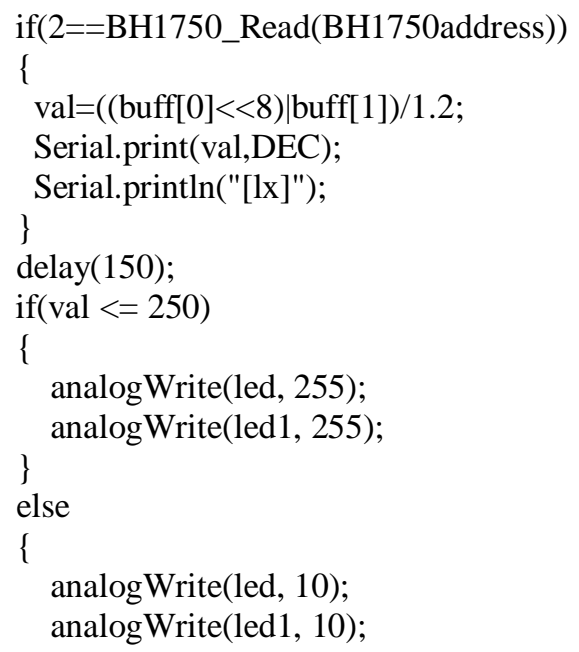

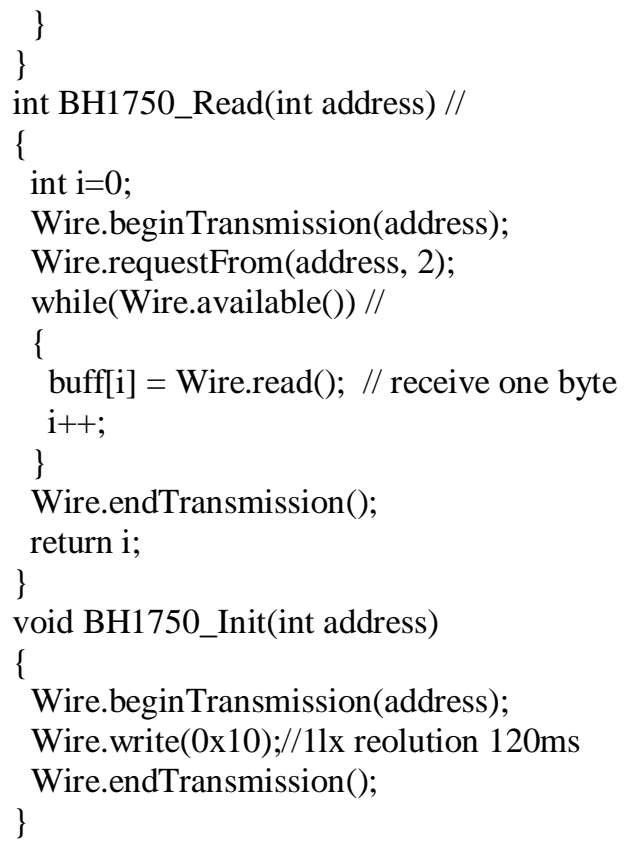

\section{OUTPUT RESULTS}

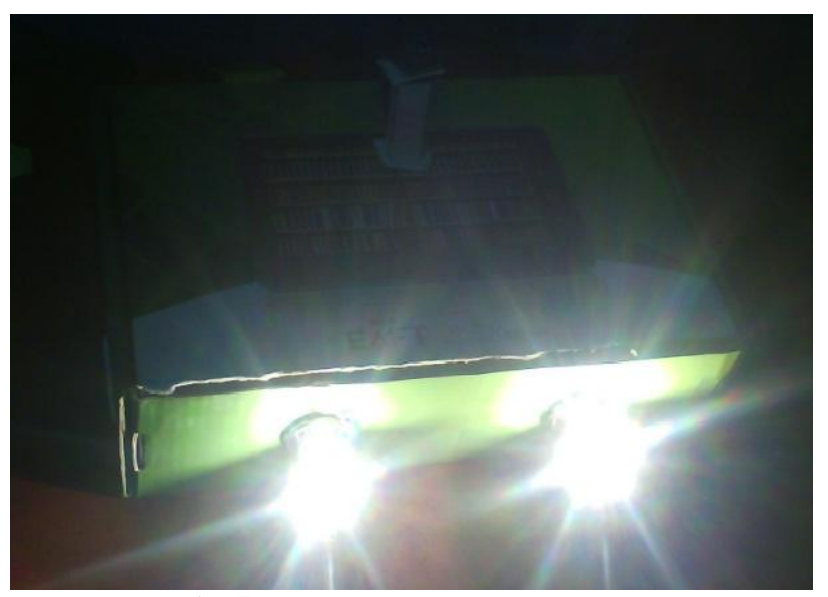

Fig-5: Output/Results of the product

\subsection{Budget Approximation}

\begin{tabular}{|cll|}
\hline Components & & Price (in Rs.) \\
\hline 1. & Battery & $3000 /-$ \\
\hline 2. & BH1750 & $530 /-$ \\
\hline 3. & Relay & $25 /-$ \\
\hline $\begin{array}{l}\text { 4. } \\
\text { UNO }\end{array}$ & Arduino & $1500 /-$ \\
\hline 5. & Headlights & $160 /-$ \\
\hline Total & & $5215 /-$ \\
\hline
\end{tabular}

\section{CONCLUSION}

The working product thus achieves the aim of switching the beam from high to low or vice-versa. This system not only assists the driver but also protects him from the temporary blindness due to the opposing headlight glare. Thus, the product provides safety to the driver especially during the night time. The product is low cost, accurate and small in size. 


\section{ACKNOWLEDGEMENTS}

We are grateful to Dr. Uma Mudengudi, Head of the Electronics and communication department, and our guide Prof. Suhas Shirol for all the facilities provided in carrying out our project. We avail this opportunity to thank Dr. Ashok Shettar, Principal, B.V.B. College of Engineering and Technology, Hubli, for all the facilities provided to us and supporting us in all academic endeavors.

\section{REFERENCES}

[1]. http://www.micro4you.com/store/bh1750-lightsensor.html

[2].http://www.elecrow.com/wiki/index.php?title=Digital_li ght_Sensor

[3]. Automatic headlight dimmer a prototype for vehicles Muralikrishnan , B.E, Electrical and Electronics Engineering, Sri Venkateswara College of Engineering, Tamil Nadu, India IJRET: International Journal of Research in Engineering and Technology eISSN: 2319-1163 | pISSN: 2321-7308

[4].http://www.ncbi.nlm.nih.gov/pmc/articles/PMC2564438/ figure/fig3.

\section{BIOGRAPHIES}

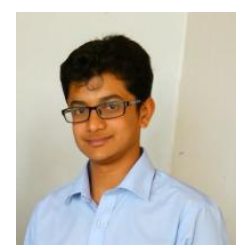

Name - Shivaji Kulkarni, CGPA - 8.98, currently pursuing $7^{\text {th }}$ semester, B.E in electronics and communication.

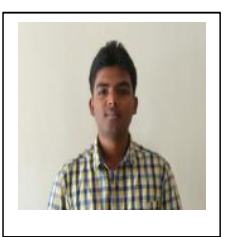

Name- Rohit Anvekar, CGPA - 7.87, currently pursuing $7^{\text {th }}$ semester, B.E in electronics and communication.

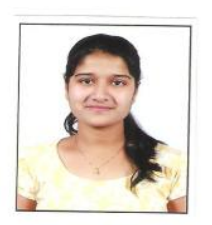

Name- Ramya Dhawle, CGPA- 9.12, currently pursuing $7^{\text {th }}$ semester, B.E in electronics and communication.

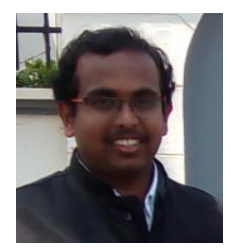

Name - Shrihari Durg, CGPA - ,currently pursuing 7th semester, B.E. in electronics and Communication. 